\title{
Health as a Means Towards Profitable Ends: mHealth Apps, User Autonomy, and Unfair Commercial Practices
}

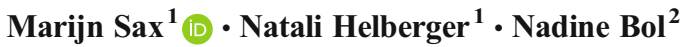

Received: 28 November 2017 / Accepted: 2 May 2018 / Published online: 22 May 2018

(C) The Author(s) 2018

\begin{abstract}
In this article, we discuss mHealth apps and their potential to influence the user's behaviour in increasingly persuasive ways. More specifically, we call attention to the fact that mHealth apps often seek to not only influence the health behaviour of users but also their economic behaviour by merging health and commercial content in ways that are hard to detect. We argue that (1) such merging of health and commercial content raises specific questions concerning the autonomy of mHealth app users, and (2) consumer law offers a promising legal lens to address questions concerning user protection in this context. Based on an empirically informed ethical analysis of autonomy, we develop a fine-grained framework that incorporates three different requirements for autonomy that we call "independence," "authenticity," and "options." This framework also differentiates between three different stages of mHealth app use, namely installing, starting to use, and continuing to use an app. As a result, user autonomy can be analysed in a nuanced and precise manner. Since the concept of autonomy plays a prominent, yet poorly understood role in unfair commercial practice law, we utilize the ethical analysis of autonomy to guide our legal analysis of the proper application of unfair commercial practice law in the mHealth app domain.
\end{abstract}

Keywords mHealth apps · Autonomy · Manipulation · Unfair commercial practices · Representative survey data

The study was supported by the Research Priority Area 'Personalised Communication' of the University of Amsterdam

Marijn Sax

m.sax@uva.nl

Natali Helberger

n.helberger@uva.nl

Nadine Bol

n.bol@uva.nl

1 Institute for Information Law (IViR), University of Amsterdam, Amsterdam, Netherlands

2 Amsterdam School of Communication Research (ASCoR), University of Amsterdam, Amsterdam, Netherlands 
A statement like "mHealth apps are concerned with the user's health behaviour" sounds like a truism; of course, mHealth apps are concerned with the user's health behaviour. Unsurprisingly, then, mHealth apps present themselves as pieces of technology that can support us in increasingly sophisticated ways in our quest for health. Take Garmin, a company that sells a wide range of wearables which should be used together with a complementary mHealth app called "Garmin Connect." This app not only collects and presents data to its users but also makes suggestions to users. "Our digital insights are tailored to your stats and habits, so they're like friendly nudges that go beyond showing the steps and stats collected by your Garmin device." ${ }^{1}$ We are told that by using such an app, the user carries a personal health coach with her all the time - one that proactively anticipates her behaviour and gently nudges her in healthy directions, right when she needs it the most.

In this article, we move beyond the truism that mHealth apps are concerned with the user's health behaviour. We call attention to the fact that mHealth apps are often also concerned with the user's economic behaviour - e.g., getting her to buy products or services. We observe that health content and commercial content are sometimes merged, in an effort to devise persuasive and profitable personalized communications that are neither purely health content nor purely advertising. It is precisely this merging of health and commerce that we are interested in. When commercial content is woven into the health content that is presented within an mHealth app, it is often difficult for users to (fully) grasp the commercial intent behind what looks, reads, and feels like health advice. This development raises questions concerning the autonomy of mHealth app users, but also about the fairness of such practices.

So far, much of the discussion about (big data-enabled) targeting and personalization strategies aimed at influencing the behaviour of individuals has concentrated on the area of data protection law. In this article, we want to broaden that perspective and turn to consumer law. More specifically, striking a balance between fair and acceptable forms of advertising, and unfair influences on consumers' decision-making, is central to the regulation of advertising in general and unfair commercial practice law in particular.

From the perspective of consumer protection, unfair commercial practice law is a promising legal lens through which to discuss the aforementioned challenges of mHealth apps, for at least two reasons. First, many of the mHealth apps currently on offer are essentially commercial apps with commercial motives, which collect valuable information about users and can establish a very personal, targeted advertising channel with them. Consequently, unfair commercial practice law is the area of law that is the most likely candidate to deal with persuasive commercial attempts to influence user behaviour by mHealth apps. Second, in the regulation of unfair commercial practices, consumer autonomy is a core value (Micklitz 2006; see also Willett 2005). The rules seek to strike a complicated balance between empowering and encouraging the consumer to take autonomous decisions, and protecting consumers from situations in which they are unable to protect themselves, either because they are in a position of vulnerability or because of the particular unfairness of the practice (Van Boom et al. 2014).

The application of unfair commercial practice law requires a sound understanding of the concept of autonomy, and how recent practices around mHealth apps affect user autonomy. However, as Micklitz has pointed out, "[o]n its own, the concept of autonomy in the Unfair Commercial Practices Directive, even in the entire European unfair trading law, seems

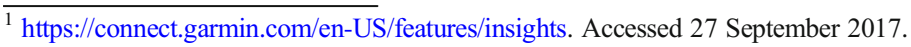


largely incomprehensible. In essence it is a legal term; however, it needs a reference point outside the legal system." (Micklitz 2006, p. 104).

It is for this reason that we first provide an ethical analysis of autonomy which will, in turn, inform our legal analysis. The question of user autonomy contains, moreover, an inherently empirical component. To evaluate mHealth practices from the perspective of autonomy, one needs to know how users are actually affected by such apps. This is why we have conducted empirical research into users' cognitive, affective, and behavioural attitudes regarding the motives and interests of mHealth apps, the persuasiveness and effectiveness of personalized messages in mHealth apps for changing behaviour, and perceived manipulative intent.

In what follows, we first discuss how mHealth apps try to influence the behaviour of users. Here, we have a particular interest in strategies that merge health and commercial content and the potential impact thereof on user autonomy. Second, we provide a conceptual discussion of autonomy and formulate three requirements for autonomy. Third, we present empirical survey data in order to gain a better understanding of how people are actually affected by personalized communications from mHealth apps. Fourth, we develop a framework for ethically evaluating commercial mHealth app practices and provide some preliminary thoughts on how the framework can be applied to cases. Here, we also refer to our survey data in an attempt to answer the question whether the ethical worries identified are already starting to materialize. Fifth and last, we draw on this conceptual framework and the resulting ethical analysis to explore how unfair commercial practice law can help protect mHealth app user autonomy.

\section{Influencing the mHealth App User's Behaviour}

All mHealth apps collect at least some data on their users; an mHealth app needs input to be able to learn something about the user's health. Simple apps, such as calorie counters, only collect one type of data and do so only a few times a day. The more sophisticated mHealth apps, such as Garmin Connect, continuously collect — through a connected wearable - data on, for instance, number of steps taken, heart rate, number of stairs climbed, intensity of movement, calories burned, and sleep pattern. The more "data rich" an mHealth app is, the more potential it offers for personalization of content. Personalized content is expected to be more persuasive in the sense of improving health outcomes (e.g., Krebs et al. 2010; Kroeze et al. 2006; Lustria et al. 2013; Noar et al. 2007) than generic content since it can convey the right message, at the right time, in the right way (Kaptein et al. 2015). In health communication, personalization is often referred to as "tailoring," which refers to presenting information such that it meets the needs of one specific individual based on distinctive characteristics of that person (Kreuter et al. 1999).

It is to be expected that personalization strategies can and will become more frequent and more powerful. Yeung (2017) has coined the term "hypernudging" to describe techniques where big data interacts with personalization in an effort to devise highly persuasive attempts to influence the behaviour of individuals. In essence, the availability of (1) lots of (personal) data, (2) behavioural-economic insights (e.g., Kaptein 2015), (3) algorithmic predictive analyses making use of lots of (personal) data and taking note of behavioural-economic insights, and (4) the "always on"-ness ${ }^{2}$ of mobile health technology makes for very potent

\footnotetext{
${ }^{2}$ People carry their smartphones with them everywhere they go and wearables are, as the name suggests, specifically designed to be worn directly on the body. As a result, people will (almost) always have these devices on them. Hence "always on"-ness.
} 
new possibilities to influence people's behaviour in a highly persuasive manner. Yeung (2017) explains:

[...] unlike the static Nudges popularized by Thaler and Sunstein (2008) such as placing a salad in front of the lasagne to encourage healthy eating, Big Data analytics nudges are extremely powerful and potent due to their networked, continuously updated, dynamic and pervasive nature (hence 'hypernudge') [...] Big Data-driven nudges make it possible for automatic enforcement to take place dynamically (Degli Esposti 2014), with both the standard and its execution being continuously updated and refined within a networked environment that enables real-time data feeds which, crucially, can be used to personalize algorithmic outputs (Rieder 2015) (Yeung 2017, pp. 118-122).

Yeung's concept of hypernudging shows the technological sophistication we can expect to be employed in the near future, aimed at influencing our behaviour. mHealth apps will provide an excellent technological infrastructure to "administer" hypernudges. Questions that have already been raised about the implications of regular nudges for the autonomy of the nudgees (Hansen and Jespersen 2013; Nys and Engelen 2016) are further exacerbated by hypernudges. As it becomes possible to personalize nudges and continually adjust their timing and content on the basis of the personal characteristics and circumstances of the nudgee, the potential to manipulate people into forming certain desires or displaying certain behaviours also grows. Hypernudges could, for instance, be used to target people with personalized communications exactly at those moments they are most susceptible to being influenced.

Technologically sophisticated personalized attempts to influence people understandably receive the attention of scholars. As we have seen, much research has been conducted on their persuasiveness for health behaviours. We, however, would also like to emphasize how mHealth apps try to influence economic behaviours by way of merging health and commercial content. This practice can be understood as a form of native advertising. Native advertising, "also called sponsored content, [...] is a term used to describe any paid advertising that takes the specific form and appearance of editorial content from the publisher itself" (Wojdynski and Evans 2016, p. 157). The employment of such merging practices is understandable from the perspective of mHealth app providers, since native advertising is notoriously hard to detect, let alone resist, by mHealth app users (Hyman et al. 2017).

Let us present some examples of merging of health and commercial content aimed at influencing the economic behaviour of users. In all cases, it could be asked to what extent we are dealing with just another form of advertising, and to what extent people are manipulated in a problematic and autonomy-eroding manner. We will come back to this exact question later in the article.

Example 1 Actify is a health platform launched by the Dutch health insurer Zilveren Kruis. Through this platform, Actify users are encouraged to install the MealMatch app which is advertised as containing tasty and healthy recipes. The recipes are commented on by dieticians, who explain why the recipe is healthy. Below the instructions for preparing the healthy food, one can find, in exactly the same font, style, and layout, a text that introduces John. Users read that it is John's mission to let everyone know that they should eat delicious healthy fish on a weekly basis. The app user is invited to click on a link to find out how "eating fish becomes a 
celebration." After the user has been addressed in terms of its health, by a health app with healthy recipes that are commented on by a health professional (i.e., dietician), the user is, after clicking on the link, directed to a Web shop that sells fish.

Example 2 The aforementioned Garmin Connect app contains a function called "Insights," which offers personalized health advice to its users. A user will, for instance, be presented with a graph showing that she logs fewer steps on Wednesdays than other days of the week, accompanied by advice on how to increase activity. Under the graph and advice, the user sees a "read more" section in the same style and layout which contains native advertising by The Cleveland Clinic. The user is invited to click on "Practice 10 healthy work habits" in the "read more" section which leads her to a website offering 10 pieces of health advice. One of these is to "learn good sleep habits." Embedded in this advice is a link to a promotion for the Go! to Sleep ${ }^{\circledR}$ 6-week sleep program which can be purchased for $\$ 40$.

Example 3 In 2015, sports apparel manufacturer Under Armour acquired ${ }^{3}$ multiple major mHealth apps, namely MyFitnessPal, Endomondo, and the MapMy app family. ${ }^{4}$ Under Armour has integrated these apps in "the world's first 24/7 connected health and fitness system" "UA Record," resulting in an mHealth app that collects data on all major domains of life: eating, sleeping, and moving. Mike Lee, Under Armour's Chief Digital Officer, has shared his vision for the future with Fortune. "Lee envisions ways to further integrate the apps so that the data can be more closely linked than it is today. For example, after tracking a run on MapMyRun, MyFitnessPal could suggest local spots where other runners enjoy a post-workout snack."6

Lee's vision for the future provides an excellent example of how the merging of health and commercial content could also be combined with hypernudges. The envisaged suggestions for healthy post-workout snacks at exactly the moment a user has finished a workout lends itself perfectly to personalized commercial suggestions that are masked as health advice. If we imagine an avid user of UA Record, then the app can use all the data collected on eating, sleeping, and moving habits to predict how the suggestions (i.e., advertising) should be personalized for the mHealth app user to be converted into a post-workout snack buyer.

Seeing the difficulty people experience in recognizing native advertising, we suggest that commercial content which is embedded in content that addresses a domain of life many people hold dear-namely health - is potentially manipulative and may threaten the autonomy of mHealth app users. Do we, as Harcourt (2015, p. 187) has put it, "turn into marketized malleable subjects who, willingly or unwittingly, allow ourselves to be nudged recommended, tracked, diagnosed and predicted"? If users do not know that they are being targeted with personalized content that intentionally obfuscates commercial intent by embedding it in health content, then they will have a hard time practising their autonomy. Moreover, even if users know (to some extent at least) that mHealth apps merge health and commerce for strategic

\footnotetext{
${ }_{3}^{3}$ This deal involved around $\$ 830$ million in total. See https://www.wsj.com/articles/under-armour-to-acquiremyfitnesspal-for-475-million-1423086478 and http://fortune.com/2015/04/21/under-armour-connected-fitness/. Both accessed 20 October 2017.

${ }^{4}$ This app family consists of MapMyRun, MapMyFitness, MapMyRide, MapMyWalk, and MapMyHike. See also: https://support.mapmyfitness.com/hc/en-us/articles/200118114-What-s-the-Difference-Between-theDifferent-MapMy-Apps-. Accessed 20 October 2017.

${ }^{5} \mathrm{https}: / /$ record.underarmour.com/. Accessed 20 October 2017.

${ }^{6}$ http://fortune.com/2016/04/05/under-armour-apps-healthier/. Accessed 20 October 2017.
} 
reasons, then the persuasive force of such strategies could still be strong enough to influence people's (economic) behaviour in ways that they - upon critical inspection - do not endorse.

To address the question of mHealth app user autonomy head on, we first need a clear understanding of what autonomy means. In the next section, we provide a conceptual analysis of autonomy. After the next section, we present an empirical study we conducted in order to better understand the empirical circumstances that shape the users' possibilities for practising their autonomy while using mHealth apps.

\section{Autonomy: Conceptual Background}

The concept of autonomy is often introduced by referring to the etymological roots of the word, namely the Greek 'autonomos' which comprises auto - self - and nomos - law. Autonomy, then, is said to be about self-government - the idea of acting on the basis of laws one has given to oneself. ${ }^{7}$ While certainly capturing the conceptual core of autonomy, the concept can be explored more precisely.

Christman (1989, p. 3) summarizes the concept of autonomy as referring to "an authentic and independent self". Starting ${ }^{8}$ with the second element-independence-we can say that a person is autonomous to the extent that she herself, and not others (hence the independence), are in control of her life. Raz (1986, p. 369), for instance, writes that "[t]he ruling idea behind the ideal of personal autonomy is that people should make their own lives." The idea of largely making and controlling one's own life can be made more concrete. Valdman (2010, p. 765) elaborates on this when he writes that "autonomous agents must exercise a kind of managerial control over the motivating elements of their psychology; they must shape their lives by deciding which elements to act on, which to shed, and which to ignore" (emphasis ours). The key term here is control: an autonomous person decides independently (i.e., controls) on the basis of which of her values, desires, and goals she acts. A person acting autonomously thus deliberates with herself as it were, taking notice of, on the one hand, the information available and the options that are open to her and, on the other hand, the "motivating elements of her psychology." She should, then, be the one who decides how her values, desires, and goals inform her intentions for acting and, thus, constitute reasons for (not) doing something. Consider the fact that in real life we often ask people for their reasons for having done something. For example, if Jenn has decided to spend her afternoon hiking through a forest, she will be able to explain afterwards that she chose to do so because the weather was nice, because she admires nature's beauty, and because she enjoys physical activity, and that these desires, goals, and values taken together served as compelling enough reasons for her to decide to go for a hike.

\footnotetext{
${ }^{7}$ See for instance Feinberg 1989, p. 27; Dworkin 1989, p. 57.

${ }^{8}$ We want to acknowledge the important insights from the literature on relational autonomy (e.g., Mackenzie and Stoljar 2000). In the following sections, we do not want to suggest that a person should only be declared autonomous if she has a perfect set of authentic desires and if her decisions are not controlled by anyone but herself. We are not arguing for completely "unencumbered selves" (Sandel 1984) as an ethical ideal. Briefly put, we acknowledge that a person can be declared autonomous if for the most important part her desires, values, and goals are authentic and if, for the most important part, she has control over the decisions she makes and the shape of her life. Moreover, people do not necessarily need the absolute largest possible range of options open to them, but they do need a sufficient number of meaningful options. It is merely for the sake of brevity and analytical clarity that we choose to discuss the different requirements for autonomy in an idealized manner.
} 
Although this requirement of independence already makes for a rather substantial account, we can add to this the requirement of authenticity. Authenticity refers to a person's relationship to her own values, desires, and goals. The idea behind this notion of authenticity is that it is one thing to have "managerial control" over the way the values, desires, and goals you happen to have inform your decisions, actions, and lifestyle, but it is quite another thing for those values, desires, and goals to be truly your own. In other words, we do not want to declare people autonomous who are stuck with values, desires, and goals they do not consider to be their own, for instance because they were manipulated into forming certain desires. More concretely then, what is required for autonomy is that the person's relationship to her own values, goals, and desires should take a certain form. Often, this "certain form" is referred to as identificationthe requirement of identifying with one's own values, desires, and goals in some sense. Different interpretations of what identification should entail exist. Some argue that a person should be able to reflect critically on one's own values, desires, and goals as they are, and should, then, endorse them (Dworkin 1989; Frankfurt 1971). Others, most prominently Christman (1991), focus on the historical process through which the desires, values, and goals developed: "what matters is what the agent thinks about the process of coming to have the desires, and whether she resists that process when (or if) given the chance" (Christman 1991, p. 10). Let us look at Jenn again. As we have already seen, her values, goals, and desires constituted compelling enough reasons for her to go for a hike. But what if we find out that those values, goals, and desires were, unbeknownst to her, evoked in her via cleverly designed personalized targeting practices that were able to detect and exploit her personal vulnerabilities. Although she has, in deciding to go for a hike, displayed perfect managerial control over the values, desires, and goals she happened to have at the moment of deciding, they turn out not to be truly hers. Or, put differently, the input for the managerial control process was inauthentic - not truly hers, meaning that this subsequent process of managerial control is tainted by this inauthentic input. She therefore lacks autonomy.

For the sake of completeness, we should add a third requirement: options. Someone can display perfect managerial control over completely authentic values, desires, and goals, but still lack the capacity for a truly autonomous life due to a lack of "an adequate range of options" (Raz 1986, p. 372). To return to the example of Jenn again: if she has the authentic life goal to hike through forests as much as she can, but finds herself living in a time and place in which there are no forests left, she lacks the material conditions - i.e., an adequate range of options - to be fully autonomous. This is true even if all of her values, desires, and goals are authentically hers and if she has perfect managerial control over them.

When we say that autonomy is valuable, we can refer back to precisely these three requirements of independence, authenticity, and options. We value autonomy because we want to be the ones who are ultimately in control over our own lives. We want to be the ones who decide what we do and for what reasons. We want to be sure that the way we shape and give direction to our life is informed by what we truly care about. We want to live, moreover, in societies in which we are actually able to shape our lives in significantly different, self-chosen ways.

\section{Empirical Insights into mHealth Perceptions}

Having identified that mHealth apps potentially pose a challenge to user autonomy, and having discussed how autonomy should be understood, our next step is to explore whether and how user autonomy actually is affected when considering the merging of health and commercial 
content in mHealth apps. This, however, is a challenging task. It is difficult - if possible at all - to directly measure autonomy, or the separate requirements for autonomy. Asking users directly whether they feel their autonomy has been violated also does not work, since autonomy is a very complex concept (as the previous section shows). We have therefore opted for an approach of asking users and non-users about their attitudes towards specific mHealth app practices that potentially give rise to issues of user autonomy. The users' attitudes towards such potentially manipulative advertising strategies was captured in a large survey among a representative sample of 1029 Dutch mobile users, ${ }^{9}$ both users and non-users of mHealth apps. In this survey, we assessed people's cognitive, affective, and behavioural components of their attitudes towards mHealth apps. The cognitive component refers to beliefs, knowledge structures, and thoughts, the affective component refers to an emotional response, a gut reaction, and feelings or moods, and the behavioural component includes overt actions, behavioural intentions, and verbal statements regarding behaviour. The data thus help illuminate (1) what people know about the intentions of mHealth apps and their practices aimed at influencing users, (2) how people feel about mHealth app intentions and practices, and (3) how people think they would behave when mHealth apps are trying to influencing users. A core assumption underlying the attitude concept is that the three attitude components vary on a continuum from negative to positive thoughts, feelings, and behaviours. ${ }^{10}$ Table 1 below presents a complete overview of the mean and median scores on these attitudes in the full sample,

Table 1 Summary statistics for all variables in the total sample and divided by users and non-users $(N=1029)$

\begin{tabular}{|c|c|c|c|}
\hline & Total sample & Users & Non-users \\
\hline \multicolumn{4}{|l|}{ Cognitive attitude } \\
\hline \multicolumn{4}{|c|}{ Perceived interest of the app provider } \\
\hline Mean (SD) & $3.52(1.57)$ & $4.00(1.38)$ & $3.40(1.59)$ \\
\hline Median (Q1, Q3) & $4.00(2.00,5.00)$ & $4.00(3.00,5.00)$ & $4.00(2.00,5.00)$ \\
\hline \multicolumn{4}{|l|}{ Affective attitude } \\
\hline \multicolumn{4}{|c|}{ Scepticism towards the merging of health and commercial content } \\
\hline Mean (SD) & $4.67(1.37)$ & $4.10(1.16)$ & $4.81(1.38)$ \\
\hline Median (Q1, Q3) & $4.25(4.00,5.50)$ & $4.00(3.38,4.75)$ & $4.38(4.00,5.91)$ \\
\hline \multicolumn{4}{|c|}{ Perceived manipulative intent } \\
\hline Mean (SD) & $4.16(0.98)$ & $3.61(0.78)$ & $4.30(0.97)$ \\
\hline Median (Q1, Q3) & $4.00(3.67,4.50)$ & $3.83(3.17,4.00)$ & $4.00(3.83,4.67)$ \\
\hline \multicolumn{4}{|c|}{ Preference for personalization } \\
\hline Mean (SD) & $3.22(1.85)$ & $3.67(1.80)$ & $3.11(1.85)$ \\
\hline Median (Q1, Q3) & $4.00(1.00,5.00)$ & $4.00(2.00,5.00)$ & $3.00(1.00,5.00)$ \\
\hline \multicolumn{4}{|l|}{ Behavioural attitude } \\
\hline \multicolumn{4}{|c|}{ General expected impact of personalization } \\
\hline Mean (SD) & $4.24(1.82)$ & $4.60(1.80)$ & $4.15(1.81)$ \\
\hline Median (Q1, Q3) & $5.00(3.00,6.00)$ & $5.00(4.00,6.00)$ & $4.00(3.00,5.25)$ \\
\hline \multicolumn{4}{|c|}{ Personal expected impact of personalization } \\
\hline Mean (SD) & $3.70(1.88)$ & $4.00(1.79)$ & $3.63(1.89)$ \\
\hline Median (Q1, Q3) & $4.00(2.00,5.00)$ & $4.00(3.00,5.00)$ & $4.00(2.00,5.00)$ \\
\hline
\end{tabular}

Higher scores indicate more positive evaluations, except for scepticism and manipulative intent, where higher scores indicate higher levels of scepticism and perceived manipulative intent. Rows in bold signify statistically significant differences for at least $p<0.05$

$S D$ standard deviation, $Q 1$ the 25 th percentile of the population, $Q 3$ the 75 th percentile of the population

\footnotetext{
${ }^{9}$ See Appendix for more information about the methods of the empirical study.

${ }^{10}$ See Breckler (1984) for empirical validation of cognition, affect, and behaviour as distinct components of attitude.
} 
representative of Dutch mobile users, as well as divided into subsamples of users and nonusers of mHealth apps. We discuss the results in more detail below.

\section{Cognitive Attitudes Towards mHealth Apps}

The cognitive component in our study refers to the perceptions of the intentions of mHealth apps from the user perspective. We proposed the statement: "The main interest of app developers is the improvement of the user's health", and asked respondents to rate what they thought on a scale from 1 "totally disagree" to 7 "totally agree" as well as provide a written description of their thinking. Our results showed that only $29.0 \%$ of mobile users were on the positive side of the continuum (i.e., scored 5 or higher), whereas $42.7 \%$ of mobile users were on the negative side (i.e., scored 3 or lower), indicating that more users felt that app developers have interests other than the user's health in mind. Interestingly, we found differences between users and non-users of mHealth apps. Whereas only $26.7 \%$ of non-users believed in the positive intentions of app developers, mHealth app users were significantly more positive, with $38.1 \%$ of users believing so $\left(\chi^{2}=9.67, p=0.002\right)$. Those who did not believe in the app developer's interest in improving health mainly referred to the commercial intent and profit generation goals of the apps' developers, as illustrated by the quotes below:

"I believe that promoting the health of the user is more like a strategy, but not the goal [of the app provider]" (non-user, male, 25 yrs.)

"App developers have the primary goal of generating profits. With my/your personal data as product. The selling strategy to get these personal data is 'to improve health'." (user, male, $32 \mathrm{yrs}$.)

Those mobile users that were on a more positive note, reported their willingness to believe in the fair and sincere intentions of app developers:

"I fairly believe in the sincere intentions of the app developers" (non-user, male, $58 \mathrm{yrs}$.) "I would like to believe that [app developers have good intentions], besides the fact that they ultimately want to generate profits" (user, female, 43 yrs.)

\section{Affective Attitudes Towards mHealth Apps}

Besides the knowledge regarding the commercial intentions of app developers, we assessed the user's emotional response to and feelings about the merging of commercial and health content in mHealth apps, which we refer to as the affective component. We measured these affective attitudes by asking about users' scepticism towards the merging of commercial and health content, their perceived manipulative intent, ${ }^{11}$ and their feelings regarding receiving personalized commercial content (i.e., personalized ads) in mHealth apps. The first two were measured with well-established, validated scales, ${ }^{12,13}$ using 7-point scales,

\footnotetext{
${ }^{11}$ For the scale we used to measure this, "manipulative intent" is defined as "consumer inferences that the advertiser is attempting to persuade by inappropriate, unfair, or manipulative means" (Campbell 1995, p. 228).

${ }^{12}$ For the scepticism towards ads, see Boerman et al. (2017).

${ }^{13}$ For the perceived manipulative intent scale, see Campbell (1995) and Cotte et al. (2005).
} 
whereas the latter was measured with the statement "I prefer personalized ads over generic ads," to be rated on a scale from 1 "totally disagree" to 7 "totally agree," including the option to expand on their answer in a written comment.

Our data showed that mobile users reported on average moderately high levels of scepticism (i.e., above the mid-point of the scale, $M=4.67, S D=1.37, N=1027$ ), and average levels of perceived manipulative intent (i.e., slightly above the mid-point of the scale, $M=4.16, S D=$ $0.98, N=1028$ ). Again, mHealth app users seemed more on the positive side of the continuum compared with non-users. Compared to non-users, mHealth app users are significantly less sceptical $\left(M_{\text {users }}=4.10, S D=1.16\right.$ vs. $\left.M_{\text {non-users }}=4.81, S D=1.38, p<0.001\right)$ and also perceive mHealth apps as less manipulative $\left(M_{\text {users }}=3.61, S D=0.78\right.$ vs. $M_{\text {non-users }}=4.30, S D=$ $0.97, p<0.001)$. Furthermore, compared to non-users, users were significantly more positive about personalized ads compared to generic ads (users $38.1 \%$ vs. non-users $26.5 \%, \chi^{2}=10.08$, $p=0.002$ ). The quotes below illustrate the feelings respondents expressed when asked to elaborate on their negative rating:

"I smell manipulation here. If I (could) see all ads, this would give me a feeling of freedom of choice." (non-user, female, 58 yrs.)

"I don't want apps to use my private information. Also not to show me ads." (user, male, 68 yrs.)

Mobile users who preferred personalized ads over generic ads often mentioned that personalized ads could contain useful information since it better matched the need, preferences, and interests of the user:

"Then it is most likely that it [the ad] is useful" (non-user, male, 22 yrs.)

"It is interesting to receive offers or information that match my needs and interests" (user, female, 38 yrs.)

\section{Behavioural Attitudes Towards mHealth Apps}

The third and final attitude component is the behavioural component and includes verbal statements about the perceived persuasive impact of personalized ads on behaviour. We proposed two statements, which could be rated on a scale from 1 "totally disagree" to 7 "totally agree" as well as the opportunity to provide written comments. The statements were: "Personalised ads are more persuasive than generic ads" and "Personalised ads are better capable of influencing my behaviour than generic ads." As is shown by our data, $50.3 \%$ of mobile users believe that personalized commercial content, such as personalized ads, is in general perceived as more persuasive than generic content. Interestingly, users have, compared to non-users, significantly more confidence in the persuasiveness of such personalized commercial content in general: $62.0 \%$ of mHealth app users versus $47.5 \%$ of non-users $\left(\chi^{2}=13.24, p<0.001\right)$. Both users and non-users mention that personalized ads could more easily "make you click":

"Personalised ads are more persuasive because you are probably more interested in the topic, which make you click more easily" (non-user, male, 25 yrs.) 
"People feel more inclined to engage with personalized advertisement. By using personalization, an artificial bond of trust between app and user is created" (user, male, $26 \mathrm{yrs}$.)

On the other hand, concerns were raised about the trustworthiness of such personalized efforts, which are illustrated by these quotes:

"I don't trust these [personalized] advertisements" (non-user, female, 72 yrs.)

"I would distrust these [personalized] advertisements" (non-user, female, 62 yrs.)

When asked about the influence of personalized commercial content on their own behaviour, users again report a significantly higher belief in the effectiveness of such targeting practices than non-users: $43.9 \%$ of mHealth app users versus $35.5 \%$ of non-users $\left(\chi^{2}=4.58\right.$, $p=0.032$ ). However, both users and non-users agree that personalized ads could be more persuasive, as illustrated by the quotes below:

"I am not 100\% immune for such (personalized) influences" (non-user, male, 38 yrs.) "If advertisers know my buying behaviour, for example by using cookies and showing me targeted ads, the chance I will fall for certain offers is much bigger" (user, male, 73 yrs.)

At the same time, users as well as non-users mentioned that personalized ads would not influence their behaviour, and stress their own control over their behaviour:

"It smells like a malicious form of manipulation" (non-user, female, $80 \mathrm{yrs}$.)

"Ads do not influence my behaviour, I decide for myself when I need something and what that will be" (user, female, 38 yrs.)

In sum, we see that, overall, people are fairly sceptical of the intentions of mHealth app providers, although users are significantly less sceptical than non-users. When it comes to affective attitudes towards commercial mHealth app practices, we see that people do not dismiss such practices outright, but that worries concerning, for instance, manipulative intent do exist. Interestingly, we see, again, that users of mHealth apps have significantly less negative affective attitudes than non-users. Lastly, we see that about half of all people surveyed believe that personalized commercial content is more persuasive than generic content. Again, it turns out that users have significantly more confidence in personalized content being able to influence behaviour than non-users.

To inform our ethical and legal analyses, we now integrate these empirical insights into the ethical and legal discussion about mHealth apps. Throughout the analyses, we make use of the empirical data just presented to (1) explain that users share many of the ethical concerns discussed and (2) interpret to what extent mHealth apps actually threaten to violate user autonomy.

\section{Evaluating mHealth Apps from an Autonomy Perspective}

The open question that requires an answer now is how attempts by mHealth apps to influence the economic behaviour of users that rely on a merging of health and commercial content 
should be evaluated from the perspective of autonomy. Let us, for the purpose of clarity, presume that all people who use mHealth apps are not explicitly forced or coerced to do so. How could questions concerning user autonomy still arise? It is, after all, people themselves who install health apps and, as a result, bring such apps inside their decisional sphere. As a start, we introduce some analytical distinctions that can lend precision to our analysis.

First, we identify three "stages" of mHealth app usage: (1) the decision to install an mHealth app; (2) the decision to start using an mHealth app; (3) and the decision to continue using mHealth apps for longer periods of time. By employing this distinction, we avoid talking about "the use of mHealth apps" as if this is a unitary phenomenon. At these different stages, different user motivations and different strategies to influence users can be observed. Ethical and legal evaluations can change accordingly.

Second, attempts to influence users' health-related behaviour and attempts to influence users' economic behaviour are to be separated analytically. Although our argument focuses on the increased merging of the two, an analytic separation of both is necessary to understand what is merged and why this could be problematic.

Third, it makes little sense to analyse potential threats to user autonomy without paying careful attention to the three different requirements for autonomy we identified: independence, authenticity, and options. Autonomy is not a binary concept that either is or is not the case - it allows for a more nuanced understanding along the lines of these three requirements.

In our analysis of user autonomy in relation to mHealth apps, we will focus on the different "stages" of use and see which of the different elements of autonomy could come under pressure. This approach also allows us to do away with the naïve image of a user who freely chooses to install a health app and therefore is declared sufficiently autonomous throughout all the stages of using the app.

\section{Installing an mHealth App}

Let us start with a person's initial decision to install an mHealth app. How could a user's autonomy possibly be violated at this initial stage? Short of outright coercion, the decision to install an mHealth app will be preceded by a person's desire to install the app. Such a desire, however, can be non-autonomous even if a person does in fact have the desire, for instance when the person is manipulated into forming the desire.

A recent example helps to illustrate the possibility of manipulating individuals into forming certain desires. In May 2017, a confidential Facebook document was leaked (News.com.au 2017). This document detailed how Facebook's algorithms "can determine, and allow advertisers to pinpoint, "moments when young people need a confidence boost" (ArsTechnica 2017). Moreover, the document showed "a particular interest in helping advertisers target moments in which young users are interested in 'looking good and body confidence' or 'working out and losing weight"” (ArsTechnica 2017).

If individuals are targeted with health content or advertising for health products at such moments of immediately felt vulnerability, both the requirements of independence and authenticity could be violated. Targeting people at the exact moments in which they "need a confidence boost" with health content that discusses how, for instance, certain mHealth apps can help them achieve a stellar body can plausibly be expected to evoke in individuals the desire to use mHealth apps. This could be further enabled by framing the commercial offer to install an mHealth app in terms of health. Since health is an all-purpose good, it is the perfect vehicle for commercial content; by framing the commercial offer in terms of health, it gains a 
sense of innocence. This is aptly captured by one of our respondents: "the reason they make an [mHealth] app is not to improve my health but to make money. The app is the means towards the end" (non-user, male, 23 yrs). Resulting desires are not authentic if people have them mainly as a result of being targeted in a certain way or the communications being framed a certain way, instead of truly wanting to have those desires irrespective of how they were evoked.

Similarly, there is a risk that such targeting practices can lead to a (partial) bypassing of individuals" "managerial control over the motivating elements of their psychology" (Valdman 2010, p. 765). The fact that many people in our survey admit that they do in fact believe that personalized content does a better job at influencing their behaviour than generic content suggests that this is not merely a theoretical possibility (see "Behavioural Attitudes Towards mHealth Apps" section). In practice, this could mean that targeting people at the exact moment they experience a moment of vulnerability that puts them into a temporal state of decreased capacity for reflective reasoning could lead to them not properly considering what is offered to them at that moment. Even in less dramatic cases where people are not personally targeted on the basis of their vulnerabilities, the merging of health advice with the commercially motivated gestures towards installing an mHealth app could still circumvent people's independent decision-making. If the health narrative used distracts people from the commercial interests and intentions at play, and if people do have independent reasons for wanting to consider commercial interests and intentions, then obfuscating those commercial considerations could violate the requirement for independence.

Moreover, targeting practices (whether vulnerability-based or not) could lead people to not consider other options they, under more ideal circumstances, would have considered and maybe even preferred. Autonomy could be violated as a result, if options that matter to a person are materially obscured.

\section{Starting and Continuing to Use a Health App}

We make an analytical distinction between first starting to use and then continuing to use an mHealth app because this allows us to bring into focus one very important feature: Through usage, a sort of "relationship" between user and app develops over time. The development of this relationship is an open-ended process, the outcome of which depends on both how a particular user interacts with the app and how the app (or its algorithms) turn these interactions into personalized outputs that in turn influence the user. Of course, the longer the user uses an mHealth app, the better the app gets to know the user, which means that the longer the relationship lasts, the greater the potential for persuasive attempts to influence (economic) behaviour becomes.

\section{Authenticity}

Let us start with the authenticity of a user's desire to continue to use an mHealth app for extended periods of time. During the development of the user-app relationship, the mHealth app has, from a commercial perspective, a great interest in retaining the user as a continuous user of the app. As long as the user uses the app, the app has a direct channel to present the user with advertising (possibly advertising that is woven into health content), and, moreover, the app can continue to collect commercially valuable 
(personal) user data. ${ }^{14}$ Getting the user to continue to use the app could therefore be understood as getting the user to display certain economic behaviour.

As a result, mHealth apps also have an incentive to get the user to see her health as a neverending quest (Devisch 2013). Even if a user is already in great health, an mHealth app will likely suggest that good health must be maintained and, moreover, that it is always possible to become even more healthy. Many mHealth apps employ a narrative that explicitly links (being preoccupied with one's) health with happiness and well-being-i.e., with living a good life. For example, Fitbit explicitly states that with Fitbit you will "live better"" 15 and Lifesum, another popular app, states that it helps people live "healthier, happier lives." 16 The framing of the continued use of an mHealth app as a matter of health and well-being could distract people from the fact that they are in fact also entering into an economic relationship - which stimulates particular economic behaviour - when they continue to use the app. It must therefore be asked to what extent a user has a truly authentic desire to continue to use a particular mHealth app and to what extent she has been made $e^{17}$ to desire the continued usage of the app by the constant emphases on health. If the latter is the case, user autonomy is - at least partially—violated.

The longer a user uses an mHealth app, the better the mHealth app knows "what makes the user tick" (Kaptein 2015). From a technological perspective, this increases the potential to devise highly personalized advertising (possibly merged with health content) that is especially capable of evoking unauthentic economic desires in users. Consider the following example. Ella has a full-time job which demands a lot of energy. Although she would like to work out more often because she is somewhat insecure about her body, she often ends up on the couch after work. When she sits on the couch, she often experiences feelings of guilt for not working out. Now, if Ella had been using an mHealth app for a long time, the app may have worked out that she is often inactive during evening hours, while she would in fact like to work out more. As a result, the app concludes that Ella is most responsive to commercial health-related suggestions on working days during the evening hours. The app now presents her with health advice that elaborates on the importance of working out, while also presenting her with suggested further information on yoga as a great way to become both healthier and happier. This further information then includes a personalized offer for Ella for a discount on Yoga Lifestyle Magazine, ${ }^{18}$ which promises to help her gain motivation for yoga and can help her enjoy yoga to the fullest. Ella proceeds to buy the subscription.

Now, it can be said that no harm is done here, since the Yoga Lifestyle Magazine subscription might lead her to live a healthier life, which is what she authentically desires. The offer could then be interpreted as being especially relevant for Ella. Some of our respondents also indicated that they do not mind personalized offers, as long as they are perceived as relevant (see "Affective Attitudes Towards mHealth Apps" section). At the same time, we should ask the critical question whether the personalized targeting described may have led Ella to buy a magazine subscription she does not truly want to have. If it was the

\footnotetext{
${ }^{14}$ The collection of user data can itself be understood as a commercial activity since the business models of apps often depend on the exploitation of user data. For a more elaborate analysis of such business models, see Sax (2016).

${ }^{15} \mathrm{https} / / /$ www.fitbit.com/. Accessed 27 September 2017.

$16 \mathrm{http} / / /$ jobs.lifesum.com/. Accessed 27 September 2017.

${ }^{17}$ For an in-depth explanation of how mobile apps can be specifically designed so as to get people "hooked" on them, see Eyal (2014).

18 This is a fictional example of a magazine.
} 
targeting during a moment of guilt which successfully made her desire the subscription, her autonomy is - at least partly_violated. The fact that people do draw relatively strong inferences of manipulative intent in mHealth apps (see "Affective Attitudes Towards mHealth Apps" section) suggests that people do not simply accept all forms of influencing behaviour under the guise of "health improvement."

\section{Independence}

We now turn to the requirement of independence. The main question to ask is whether tactics of merging health and commercial content - possibly coupled with personalized targeting — are aimed at circumventing the user's "managerial control" over her desires, values, and goals. We can look at Ella's case again, which can also be analysed from an independence perspective. First, let us look at the careful merging of health and commerce. If Ella is presented with what feels, looks, and reads like health advice, and is, as a result, put in a health mind-set, she might be much more inclined to go along with the economic suggestions made to her. In the previous section, we suggested this could be the result of unauthentic desires being evoked. Here, we want to suggest that it could also be a case of her not considering the commercial content and intent found within the health advice at all, precisely because she is put in a "health mind-set" and not in an "economic decision-making mind-set." If Ella ends up displaying economic behaviour she has not independently decided to display, this would breach the independence requirement.

Like with the instilment of unauthentic desires, the circumvention of a user's independent decision-making capabilities can be achieved even more effectively by highly personalized communications that personalize not only content but also timing. In the case of Ella, the chances of circumventing her independent decision-making capabilities are highest when she is targeted with commercial health content while she sits on her couch regretting another evening of not working out. Continued use over time could thus enhance potential for practices that breach the independence requirement.

\section{Options}

Lastly, we turn to options. It should be asked whether highly personalized commercial targeting in mHealth apps might materially obscure other valuable options the user would have wanted to consider had the personalized commercial targeting not occurred. This question is especially pressing in cases where commercial content is integrated in health advice. As a result of being presented with health content within an mHealth app and being addressed in terms of health, a user may end up with a mind-set that makes it harder/less likely for her to play the role of the critical and reasonably circumspect consumer who makes a proper economic assessment of the offer. She is, after all, addressed in terms of her health, not as a consumer.

\section{Tentative Exploration of the Empirical Circumstances of User Autonomy}

Thus far, we have discussed what it means, conceptually speaking, for autonomy to be violated which, in effect, has helped us to understand how user autonomy can be violated. Another important question, however, is to what extent the empirical circumstances actually enable users to practice their autonomy. Although our data do not allow us to map these empirical circumstances fully, we can use the cognitive, affective, and behavioural components of 
people's attitudes towards mHealth apps to tentatively explore the empirical circumstances of user autonomy.

Broadly speaking, the results can be interpreted as indicating that people (1) believe that personalization in mHealth apps can in fact be rather efficacious when it comes to influencing behaviour and (2) believe that this can potentially be problematic. The survey thus shows that it is not just an abstract ethical analysis that judges some attempts by mHealth apps to influence behaviour to be ethically problematic. When asked, people report worries that are in line with our ethical analysis, which lends additional force and urgency to the conclusions of the ethical analysis.

For our analysis of user autonomy, the most striking finding is that those people in our sample who actually use mHealth apps tend to be more convinced of the ability of personalized advertisements in mHealth apps to change their economic behaviour, while also being less sceptical about the intentions of mHealth apps and less worried about possible manipulative intent of mHealth apps. The fact that users are significantly less sceptical than non-users, while they at the same time believe more strongly in the efficaciousness of personalized advertising in mHealth apps, could be interpreted in at least two ways.

The first interpretation is to suggest that as mHealth app users are those who have actually experienced the persuasiveness of personalized advertisements in such apps, we should conclude that they are in a better position to judge on manipulative intent and what the interests of mHealth app providers are. As a result, we should take their reported cognitive, affective, and behavioural attitudes on efficaciousness of personalization, manipulative intent, and the interests of mHealth app providers to be more authoritative than those of non-users. Following this line of thinking, it could be concluded that worries of manipulation by mHealth apps and the resulting violations of autonomy are unduly alarmist. Such a conclusion would, however, be somewhat simplistic, for it would implicitly assume that mHealth app users can and will detect all the possible ways in which mHealth apps may violate their autonomy. It is, however, perfectly possible for someone's autonomy to be violated without that person noticing it - for instance when the person has not (yet) noticed that she has acted as the result of an inauthentic desire. One could even claim that many attempts by mHealth apps to influence the economic behaviour of their users are actually designed to influence the users as imperceptibly as possible. Thus, in order to establish the empirical soundness of this interpretation, further research is needed on people's ability to detect and understand attempts that are explicitly designed to influence them in (relatively) imperceptible manners.

The second interpretation is to suggest that, generally speaking, those people who are less critical and circumspect with regard to the workings of and intentions behind digital technologies such as mHealth apps, are also the people who are much more likely to install and use mHealth apps. As a result, mHealth app users could be seen as, on average, more naïve than non-users, and as being more inclined to believe that mHealth apps will not try to influence their behaviour in problematic ways (for instance because they believe that mHealth apps only pursue laudable health-related ends). If we accept the second interpretation, it could mean that mHealth app users are especially vulnerable, precisely because they are inclined not to worry about potentially autonomy violating practices. This would leave them more susceptible to manipulation, for instance because they do not realize that mHealth app providers might have interests other than the users' health (e.g., making sure users engage with commercial content in order to generate profits). In practice, this could mean they are less likely to critically reflect on the authenticity of their desires, values, and goals, and how these inform reasons for action. Or they could be more likely to go along with the natively advertised commercial options an 
mHealth app presents to them, instead of questioning whether there might be other options they prefer, but that are significantly harder to find out about.

Although the survey data do not provide conclusive answers, they do provide clear direction for further empirical research. Empirical research into users' ability to detect and withstand potentially autonomy violating mHealth app practices would be welcome. The same holds for empirical research into the different characteristics and motivations of users versus non-users. For now, we can conclude that if the first interpretation we provided is the most sound, it implies that our analysis - for now at least - is predominantly interesting as a conceptual exercise which may help us understand potential future risks of mHealth apps violating user autonomy, and the conditions that need to be fulfilled to safeguard users' autonomy (e.g., awareness of the commercial intent). If, however, the second interpretation is the most sound, it implies that exploring the protection of mHealth app user autonomy is urgent and necessary.

\section{Protecting mHealth App User Autonomy}

The objective of this section is to investigate how the Unfair Commercial Practices Directive (UCPD) can help to identify and remedy situations in which the way mHealth apps are marketed and offered to users constitute (un)fair interferences with the users' autonomous decision-making. We incorporate the autonomy framework developed above in our legal analysis, meaning we explicitly refer to the different requirements for autonomy (independence, authenticity, and options) and the different stages of using an mHealth app (installing, starting to use, and continued use). The analysis benefits, moreover, from empirical insights into the way consumers perceive and engage with mHealth apps (see "Empirical Insights into mHealth Perceptions" section).

\section{A Closer Look at the UCPD, Its Mechanisms, and Its Workings}

Commercial practices are unfair where they are either contrary to the requirements of professional diligence, or (can) "distort the economic behaviour" of consumers (Art. 5 (2) UCPD). Such economic behaviour of consumers can include a broad range of activities along the entire life cycle of a commercial relationship with the supplier of an mHealth app, from processing advertising and deciding to (not) buy an app, to using and ceasing to use it, or exercising any contractual rights a user may have, such as compliance with contractual agreements, maintenance, and after sales services. ${ }^{19}$

Importantly, the scope of the rules is restricted to commercial practices and transactions of the consumer. The UCPD defines a "transactional decision" in Art. $2(\mathrm{k})$ as

\footnotetext{
${ }^{19}$ See also Willett (2010, p. 250), who argues that the UCPD is applicable throughout the entirely dynamic life cycle of the relationship with the trader. According to Art. 2(e) of the UCPD, "to materially distort the economic behaviour of consumers' means using a commercial practice to appreciably impair the consumer's ability to make an informed decision, thereby causing the consumer to take a transactional decision that he would not have taken otherwise." "Transactional decision" is understood in a broad sense and can include activities along the entire life cycle of a commercial relationship with a supplier, from deciding to (not) buy an app, to using and ceasing to use it, or exercising any contractual rights a user may have, such as compliance with contractual agreements, maintenance, after sales services, etc. (see the definition of transactional decision in Art. 2 (k) of the UCPD).
} 
"any decision taken by a consumer concerning whether, how and on what terms to purchase, make payment in whole or in part for, retain or dispose of a product or to exercise a contractual right in relation to the product, whether the consumer decides to act or refrain from acting." In concrete terms, this means that unfair commercial practice law cannot be used to judge the fairness of claims that mHealth apps make about their ability to contribute to a healthier, fitter life per se (particularly if those claims are not true). It does, however, apply in situations in which such claims are instrumental in selling, using or continuing to use the app.

The strong focus on "economic behaviour" and "consumer interests" has been subject to repeated critique. Wilhelmsson, for example, points to the fact that nowadays commercial considerations may be only one, and not even the most relevant aspect in the decision to use or not use certain services. Wilhelmsson refers to examples such as green or fair trade products (Wilhelmsson 2006a, p. 49). In a similar vein, Willett suggests a broad interpretation of "economic behaviour" in the sense that UCPD law is applicable "as long as there is some commercial flavour" (Willett 2010, p. 249). mHealth apps, arguably, are another example where economic and non-economic decisions fuse, as an almost inevitable consequence of the increasing commodification of the health and fitness sector (see above). With commercial mHealth apps, the decision to (continue to) use them will inherently also always be a transactional decision in the sense of the UCPD. Or put differently: the UCPD may not apply to the decision to live healthily, but it can apply to the decision to turn to commercial products and services in order to achieve that goal. ${ }^{20}$

Unfair commercial practice law draws a distinction between two broad categories of unfair commercial practices: commercial practices that are misleading and practices that are aggressive. In addition, practices that are contrary to the requirements of professional diligence can also be considered unfair. Misleading practices include either the provision of false information, or the omission of information that consumers need to make informed decisions (Arts. 6 and 7 of the UCPD). In other words, the main objective behind the ban on misleading practices is the creation and preservation of the conditions that need to be fulfilled so that users can make informed decisions. The goal here is to provide users with the (correct) information that consumers need so that they can make informed and autonomous decisions (Wilhelmsson 2006b). The provisions about aggressive practices go beyond transparency and are concerned with forms of exercising pressure or other forms of undue influence on the actual decision-making but also on users' fundamental rights, such as privacy (Howells 2006). ${ }^{21}$

In general, the rules about unfair commercial practices operate on a broad number of rather vague notions ("undue," "fair," "coercion," "harassment," etc.), leaving judges ample room for interpretation and application in certain situations. And yet, the directive also lists a number of practices that are always considered unfair (the so-called blacklist in Annex I of the UCPD). Apart from being an interpretation aid for the vaguer notions of the directive, the blacklist is also an element of ex ante consumer protection (compare Wilhelmsson 2006b).

\footnotetext{
${ }^{20}$ It is worth noting that under the directive Member States retain the right to regulate commercial practices on the grounds of the protection of the health and safety of consumers (Recital 9 UCPD), a consideration that we will revisit in the conclusions.

${ }^{21}$ Also pointing out, however, that such an understanding of the directive is difficult to reconcile with the actual wording of the directive that also requires an impact on a transactional decision.
} 


\section{mHealth Apps and Misleading Practices}

By structuring the evaluation of mHealth apps under unfair commercial practice law according to the three requirements for autonomy from the ethical analysis - independence, authenticity, and options - and by departing from the premise that an important objective of the UCPD is to protect consumers' autonomous decision-making, we will demonstrate how a more differentiated, ethical understanding of autonomy and mHealth apps can actually help to inform and sharpen the legal analysis.

\section{Independence}

Independence can be seen to refer to the agency of a consumer to make a transactional decision that is in line with her values, goals, reasons, and expectations. Accordingly, No. 17 from the list of banned commercial practices in the UCPD's Annex I seems to be a prime example of a commercial practice that conflicts with the independency requirement and that is very relevant to mHealth apps: "Falsely claiming that a product is able to cure illnesses, dysfunction or malformations." 22 In its Guidance document, the European Commission interprets the provision broadly, in the sense of also applying to wellness claims (European Commission 2016, p. 91). In other words, any advertising that falsely claims that the use of the app will lead to weight loss, less risk of heart disease, or better sleep patterns seems to affect the freedom of a consumer to take a decision that is the best approximation of her expectations. Consequently, providers of mHealth apps need to be very careful with promises such as "when using this app you will live better" or that a particular app helps people live "healthier, happier lives." 23 Needless to say, the burden to provide evidence for the effectiveness of the treatment lies with the supplier (European Commission 2016, p. 93).

Another relevant example of how commercial practices can affect the independence of the consumer's decision-making is a situation in which (personalized) health advice is driven by commercial considerations. To come back to the earlier example of John's advice to eat fish from a very particular web shop-would this practice constitute an unfair commercial practice?

Probably yes. There is little doubt that under Unfair Commercial Practice Law, hiding the commercial intent behind a commercial practice is unfair. ${ }^{24}$ The UCPD itself is also rather explicit on this point (see Article 7(2) and No. 22 of Annex I). ${ }^{25}$ Seeing the provisions from the perspective of independence as a constituent element of autonomous

\footnotetext{
${ }^{22}$ Art. 3(3) states that the directive is without prejudice to health regulation-i.e., not extending to validity of health claims or compatibility with health laws.

23 Jobs.lifesum.com. Accessed 18 October 2017.

${ }^{24}$ For instance, in its Guidance Document, the European Commission cites a decision of the Polish Office of Competition and Consumer Protection against a trader who invited consumers for free health check-ups as a strategy for presenting and marketing products (European Commission 2016, p. 71), referring to Decision No, RPZ 6/2015 of the Polish Office of Competition and Consumer Protection.

${ }^{25}$ Protecting consumers against hidden marketing is more generally an important principle in European Consumer Protection. See Art. 8(5) of the Consumer Rights Directive (direct marketing needs to be recognizable), Art. 6(a) of the E-Commerce Directive (commercial communication needs to be identifiable), Art. 9(1)(a) and (b) of the Audiovisual Media Services Directive (television advertising and teleshopping need to be recognizable, prohibition of subliminal advertising), and Art. 13(4) of the ePrivacy Directive (direct marketing needs to be recognizable).
} 
decision-making, however, helps us to better understand why such a practice must be considered unfair: by creating the false impression that the main objective of an app is to further consumers' health, and by hiding the commercial intent as another important motive, a consumer is not in full control of her decision. She simply does not have all the facts at hand that she needs to make that decision. This consideration seems even more relevant seeing our findings about the scepticism of users as to the authenticity of the intentions of commercial mHealth app providers, with almost half of non-users reporting that they draw inferences of manipulative intent (see "Empirical Insights into mHealth Perceptions" section). The fact that the decision is related to a matter as vital as health might make hiding the commercial intent even more unfair (compare Willett 2005).

Similarly, claiming that an mHealth app's sole purpose is to improve health or fitness, without mentioning that consumers are "paying" for this service (be it in the form of money, data, or attention) is an unfair commercial practice to the extent that it misleads consumers about the commercial intent of the supplier. In order to be able to freely decide on taking an independent, autonomous transactional decision, consumers must be aware that they engage in a commercial transaction in the first place.

It is worth noting that in order to qualify health advice as an unfair commercial practice, it is not necessary that the health advice is wrong per se (the fish from John's web shop may still be a healthy choice). Instead, what is relevant is that the trader has failed to point the user to the fact that John may be giving valuable health tips, but that he also has a very particular commercial interest of his own in doing so.

\section{Authenticity}

Arguably, masking the commercial intent of a message also conflicts with the second requirement for autonomous decision-making: authenticity. In a situation in which the mHealth app supplier hides the commercial intent behind the app it may be very difficult to ascertain whether the interest of the user in eating fish is the result of her own desire for eating healthy fish, or whether she was manipulated into forming that desire. Where she was manipulated, one can argue that her desire to eat fish was not truly her own desire, and hence not authentic.

The authenticity of the decision is also a relevant consideration in the context of unfair commercial practice law. Alongside providing the consumer with false information, or omitting information that the consumer needs in order to take an informed, independent decision, this practice is only considered unfair if it "causes or is likely to cause the average consumer to take a transactional decision that he would not have taken otherwise" (UCPD, Arts 6 (1) and 7 (1)). In other words, a commercial transaction is only unfair if it succeeds, or is likely to succeed in instilling feelings or desires that were not her own originally (otherwise she would have taken another transactional decision).

The example, however, also immediately demonstrates the limits of applying unfair commercial practice law: Article 7(2) UCPD does not apply if omitting commercial intent would not affect the authenticity of the decision, in the sense that the consumer would have decided differently had she known that the app also serves a commercial purpose. As the results from the survey showed, many users seem to actually believe that mHealth apps also pursue commercial objectives. The fact that such apps are typically downloaded from an "app store" can be another contextual factor that may indicate to 
consumers that health advice is not for free. ${ }^{26}$ In this respect, the approach of the UCPD is very pragmatic: it does not ban the fusion between health advice and commercial communication per se, only in situations which are likely to mislead consumers. "The trader is liable only when there has been some form of voluntary 'assumption of responsibility' for the information, rather than simply where consumers 'need' the information to take an informed decision" (Willett 2010, p. 255). In other words, the UCPD does not purport to protect autonomous decision-making in its own right (because, for instance, it is an important value in our society), but only as a reflex of the quality of commercial decision-making.

However, it is worth noting that fusions between editorial and commercial content in the media are banned outright by the directive. Using "editorial content in the media to promote a product where a trader has paid for the promotion without making that clear in the content or by images or sounds clearly identifiable by the consumer (advertorial)" is considered a commercial practice that is always unfair (and hence banned) (UCPD, Annex I, No. 11). ${ }^{27}$ This categorical ban on advertorials in the media takes into account public interest considerations regarding trust in, and the functioning of, the media, as well as the specific and very sensitive interest that consumers have in media content. Because of the central role that the media play in the democratic process and public debate, it is considered critical that users are able to judge for themselves the authenticity of the programming, or whether it has been influenced by external, commercial influences. This is also an expression of users' protected fundamental right to freedom of expression (Schaar 2008; Kabel 2008). Health does not stand back in terms of importance or relevancy to the ability to exercise one's fundamental rights (e.g., the right to privacy and life). Seen from this perspective, an argument can be made in favour of a different weighting of the economic freedom of the supplier, and hence more protection for consumers from camouflaged advertising, in the case of mHealth apps as well. More so as the clear indication of commercial intent is more generally a well-recognized principle in consumer law. ${ }^{28}$ These could be reasons to argue, for example, that there is a need to extend No. 11 of Annex I to not only editorially camouflaged media advertising but also advertising that is masked as health advice. ${ }^{29}$

\section{Options}

This leaves the question of how free users are to exercise choice from different options, and even whether they have options at all? If John gives himself the appearance of a trusted adviser for users of that particular app, is he materially obscuring the option to turn to other suppliers of omega fats? In the logic of unfair commercial practice law, consumers' choice from different options could be limited in at least two ways: consumers do not have the information they need to decide between different options, or they lack information as to what their options (e.g., competing products and

\footnotetext{
${ }^{26}$ Something different could apply to pre-installed health apps that consumers did not download themselves and may consider to be a complimentary service by the mobile phone operator.

${ }^{27}$ In a similar vein: according to Art. 9(1)(a) and (b) of the Audiovisual Media Services Directive television advertising and teleshopping need to be recognizable, and subliminal advertising is prohibited.

${ }^{28}$ Art. 8(5) of the Consumer Rights Directive (direct marketing needs to be recognizable), Art. 6(a) of the ECommerce Directive (commercial communication needs to be identifiable), Art. 9(1)(a) and (b) of the Audiovisual Media Services Directive (television advertising and teleshopping need to be recognizable, prohibition of subliminal advertising), and Art. 13(4) of the ePrivacy Directive (direct marketing needs to be recognizable).

${ }^{29}$ Having said that, the list is exhaustive, a fact that has not been left uncriticized, see e.g., Wilhelmsson (2006b, p. 159).
} 
services) actually are. For the given example: John linked only to his own fish shop, not to others. One may wonder, however, to what extent this lack of indication of other options is sufficient to lead consumers to take decisions that they would not have taken otherwise. After all, most, if not all, consumers will know that John's is not the only fish shop around. Consequently, additional circumstances would probably be needed to justify the finding of an unfair commercial practice, which brings us to the second category of unfair practices: aggressive commercial practices.

\section{mHealth Apps and Aggressive Practices}

At the core of the provisions on aggressive practices are not so much information needs (as in the provisions about misleading practices), but the protection of freedom of choice of consumers and finding the balance between legitimate persuasion and aggressive selling (Howells 2006). Therefore, the potential relevancy of the rules about aggressive practices as an instrument to protect autonomous decision-making in the context of mHealth apps as well is evident, as being able to choose from different options is an important element of autonomous decisionmaking. Having said this, the provisions on aggressive practices are perhaps even less well defined than the provisions on misleading practices. Howells (2006, p. 168) writes that " $[t]$ he balance between legitimate persuasion on the one hand and harassment, coercion and undue influence can be hard to fix in many instances and the Directive is not particularly helpful in assisting with drawing those boundaries." Hence, the ethical requirements for autonomous decision-making defined earlier could provide a useful source of concretisation.

The provisions about aggressive practices ban restriction of autonomous choices by physical or psychological pressure, in the form of harassment, coercion, or undue influence (UCPD, Art. 8). The division between the three is not always easily made (Howells 2006). Arguably, the provisions on undue influence relate more closely to the exercise of psychological pressure and, here in particular, the exploitation of power imbalances. ${ }^{30}$ This can be the exploitation of market power in the sense that suppliers (ab)use the fact that consumers have no choice to pressure them into buying products and services that they would otherwise not have bought. But this could also be "persuasion power." Willett gives the example of greater market understanding and negotiation skills (Willett 2010, a critical analysis if provided by Howells 2006). Arguably, this could also be power in the form of detailed knowledge of the user, her wishes, fears, preferences, and biases but also the ability to serve users with personalized recommendations. As explained earlier, personalized recommendations can be potentially more persuasive, e.g., able to influence consumers' behaviour (be it health or economic behaviour). Interestingly, in our survey, users themselves indicated that personalized content could not only be generally more persuasive, but also more effective in impacting one's own behaviour (see "Behavioural Attitudes Towards mHealth Apps" section). As difficult as it may be to base any normative conclusions on such self-reported behaviour, these findings do seem to further emphasize the urgency of scrutiny of such practices under unfair commercial practice law.

When then do personalized health recommendations cross the border between being a useful, tailor-made service, and constituting undue influence in the form of exercising manipulative power over the user? Here, the earlier specification of autonomous decision-making

\footnotetext{
${ }^{30}$ The directive itself describes undue influence as "exploiting a position of power in relation to the consumer so as to apply pressure, even without using or threatening to use physical force, in a way which significantly limits the consumer's ability to make an informed decision," Art. 2 (j) UCPD.
} 
into its three requirements - independence, authenticity, and options - can again help in informing the answer to that question. As we explained earlier, choices are not (fully) autonomous when, in the process of either buying, deciding to use, or continuing to use a health app, one or more of the three requirements are not fulfilled.

\section{Lack of Options}

To come back to John: Could John's rather rude redirection of consumers' intent to eat healthily to his own fish shop have reduced the options of consumers to shop for their fish elsewhere? In many respects, the case resembles the situation of one of the classic examples of an aggressive practice: doorstep selling. Traditionally, this has been a situation in which a seller is ringing at the user's home door and trying to sell products at the doorstep. Doorstep pressure selling is a classic example of the abuse of a situational monopoly (Habersack 2000). A situational monopoly refers to a situation in which it is not the control over particular assets that grants a competitor a dominant market position, but the ability to control the options that a user has (e.g., being the first to arrive on that market, being able to exclude competitors, or exploiting a particular trust relationship). Such practices are explicitly banned by the UCPD: "Conducting personal visits to the consumer's home ignoring the consumer's request to leave" is an example of a commercial practice that is always considered unfair (UCPD, Annex I, No. 25). Seen from this perspective, approaching someone in the privacy of their home can also imply making use of a situation in which no other providers of competing products are potentially present (in contrast to a public market space). Privacy in that sense can also place consumers at a disadvantage, precisely because others are excluded from access, thereby reducing their choice from other, potentially competing offers.

In redirecting users to his fish shop, John may have been essentially reducing the users' options and, in so doing, abusing the virtual equivalent of a "situational monopoly" in the real world. In the digital world, suppliers do not come to doorsteps anymore. They do not need to: they have a far more effective and arguably more private opportunity to access the consumer, via the screen of her telephone or fitness tracker. Therefore, using this privileged position in the virtual, and in that moment very private, marketplace is a practice that deserves scrutiny under the UCPD.

Another example of unfair restriction of choice could be a variation on another classical, though probably extreme, case of aggressive practice: the refusal to allow a consumer to leave the premises before he has concluded the contract (UCPD, Annex I, No. 24). Again, this is an example that could potentially get a new meaning when transferred to the context of mHealth apps, particularly in cases where fitness trackers are involved. Often, these are proprietary platforms that will only give external parties/advertisers limited access (Trans Atlantic Consumer Dialogue 2008), thereby effectively limiting the options that users have on that platform. Once a consumer has purchased a particular fitness tracker the proprietary character of the platform and lack of interoperability can restrict her option to use fitness apps from other suppliers. Similarly, to the extent that consumers are not able to port their data from one platform to another, this also has also an effect on their freedom to choose from different options. This is not to say that the lack of interoperability is per se and always constitutes an unfair commercial practice. It can, however, when the lack of alternatives is used to "pressure" consumers into using particular health apps.

A final example of lack of options to be discussed here is situations in which consumers are not free to choose in favour of or against using a particular health app in the first place. An example could be a situation in which an insurance company makes the provision of certain 
terms and conditions dependent on the use of a fitness tracker. The requirement to use a fitness tracker could constitute an unfair commercial practice if in effect users feel pressured into using it. $^{31}$

Alongside coercion, aggressive commercial practices can also include more subtle pressure on consumers' decision-making in the form of "undue influence."

\section{Lacking Independence of the Decision}

An indication of undue influence over mHealth app users could then be if the supplier exercises his influence in a way to make it impossible for the user to decide independently, i.e., when a practice circumvents the managerial control of users over their own desires, values, and goals (see “Autonomy: Conceptual Background" section). To some extent, this element of independence is also reflected in the UCPD's definition of undue influence as the limited "ability to make an informed decision," 32 though the focus in the independence criterion is probably more on circumventing or even excluding consumers' ability to decide, without the influence of third parties, on the basis of their own desires, goals, and values. We earlier gave the example of the Australian teens who can be targeted on the basis of their emotions, doubts, and negative selfperception. And indeed, the exploitation of concerns (e.g., being too heavy or not fit enough) or fears (becoming ill, not having friends, not being considered attractive) has been acknowledged as one possible form of exercising undue influence (Willet 2010; Schulze and Schulte-Nölke 2003). ${ }^{33}$ An example of undue influence could then be if, based on the information that suppliers have over users - their fears, concerns, and emotions - suppliers use that (data-driven) knowledge to identify moments in which consumers are particular sensitive to personalized persuasive strategies (e.g., because they feel particularly unattractive, unhealthy, or emotional at that moment). At such moments, individuals may temporarily lack the ability to make a truly independent decision. Another instance of undue influence could be if the knowledge about fears and health concerns is used very purposefully to circumvent users' emotional and rational control mechanisms, and so to target them with commercial promises of more and better health or fitness. Or, as Micklitz (2006, p. 105) has put it: "The touchstone of the autonomy concept of the consumer is the assessment of emotional advertising."

Similarly, according to comparative research by Schulze and Schulte-Nölke (2003) on the notion of fairness in European Member States, exploiting special feelings of trust that consumers display towards third parties can also constitute an aggressive practice and is in some countries (e.g., Germany) even explicitly regulated. The example that they give is a school teacher or a chairman of a workers' council (Schulze and Schulte-Nölke 2003), but an example closer to the present case could be a health care provider or, by extension, even the provider of an mHealth app. Again, one can argue that in such situations users' independence

\footnotetext{
${ }^{31}$ Apart from that, exercising pressure on consumers to agree to the use of fitness apps could also make consent under data protection law unfree, with the consequence that the processing would not be lawful—which would also mean that continuing to use the data that are the result of that processing could be in conflict with the professional diligence requirement of the UCPD (and hence constitute, at the same time, an unfair commercial practice).

32 See also Recital 6 UCPD: "impairing the consumer's ability to make an informed decision."

${ }^{33}$ Schulze and Schulte-Nölke 2003 present examples from different European Member States' case law. See also Incardona and Poncibò (2007, p. 33).
} 
of decision-making is affected (because they rely so strongly on a third party to guide their decisions).

\section{Lack of Authenticity of the Decision}

We have already discussed how withholding information that the consumer might need, or misleading consumers about the commercial intent of a personalized communication, can conflict with the authenticity requirement. Aside from camouflaging the commercial intent, however, there can also be a situation where the supplier of an app goes further than withholding information. The detailed knowledge about their users, their concerns, level of fitness, etc. can also translate into a position of power that allows a supplier to exercise direct influence over the desires, concerns, or fears of a user. In other words, that knowledge can also be used to actively manipulate the user and instil desires, concerns, and fears in her that she did not have in the first place - and does not genuinely want to have - thereby tainting the authenticity of consumers' desires and affecting the consumers' ability to make an informed decision.

"Undue influence" is defined by the directive as meaning "exploiting a position of power in relation to the consumer so as to apply pressure, even without using or threatening to use physical force, in a way which significantly limits the consumer's ability to make an informed decision" (UCPD, Art. 2 (j)).

Kaptein's research into "persuasion profiles" shows how effective data can be used to identify the persuasion strategy that works best for an individual user (Kaptein 2015; see also Hanson and Kysar 1999). Others refer to "mental marketing" in the sense of commercial messages that "are not consciously perceived or evaluated but still might influence behaviour" (Petty and Andrews 2008, p.7). Our survey results seem to be pointing in that direction, too, with the majority of consumers believing that personalized messages (i.e., messages that use data to target the consumer) are potentially more effective and persuasive. The difficult question for consumer law in general, and unfair commercial practice law in particular, then, is where to draw the line between perfectly legitimate instances of advertising (as all advertising is about exercising influence, Gómez Pomar 2006) (34 $^{34}$ and unfair manipulation.

Again, ethics, and the authenticity requirement in particular, may provide useful help in interpretation. To recall, one critical element of autonomous decision-making is to not only have managerial control over one's values, desires, and goals but that they are also truly one's own. Using detailed information (data) about users to target advertising for products that are likely to respond to a consumer's values and desires is not per se making these values and desires less authentic. But consumers make transactional decisions not only on a rational level. There is a significant body of scholarship telling us that consumers are not rational decision makers, but that other factors, such as hidden biases but also emotions, too, play a critical role in consumer decision-making (Kahneman 2011; Thaler and Sunstein 2008; Reisch et al. 2013). Accordingly, another form of undue influence to fall under the Unfair Commercial Practice Directive could be influencing the attitudes towards, or the weighing of, these values and desires. Based on Kahneman's dual process theory, Hansen and Jespersen observed that not all forms of influencing choices are the result of reflective thinking, some also affect

\footnotetext{
${ }^{34}$ Gómez Pomar also points to the prohibitive enforcement costs if almost any form of commercial communication was to be qualified as manipulative, and hence unfair (Gómez Pomar 2006, p. 8).
} 
automatic modes of thinking, in the sense of reflexes, instincts, and routine actions which we perform without really making a conscious decision (what they refer to as system 1 thinking). Following this line of thought, one could argue that instances of unfair manipulation occur only where signals (or nudges) seek to influence system 1 thinking in a way that is not transparent (and hence unnoticed) to the user (Hansen \& Jespersen 2013). Similarly, as Incardona and Poncibò (2007) argue, emotions and moods can actually play a surprisingly central role in consumers' decision-making. What if data power is not used to uncover (hidden) preferences and desires, but to manipulate consumers into having particular emotions that they might not have had in the first place? Seeing the importance that emotions play in consumer decision-making, the authenticity criterion could arguably also stretch to the authenticity of emotions. Howells gives the example of selling products to consumers who are seriously ill as a possible form of aggressive practice (Howells 2006). Could similar be said of consumers who feel very strongly about being healthy and fit? Considering the importance of health and the desire to lead a healthy life, a question for further exploration could also be to what extent consumers are more likely to be influenced by feelings and fears (e.g., wishing to live healthily, live longer, etc.) than consumers of other products and services.

\section{Are mHealth App Consumers More Vulnerable Consumers?}

Conceptually and legally, the qualification of a commercial practice as (un)fair cannot be seen separately from the question of who the individual consumer is, respectively what consumer standard one adopts. Unfair commercial practice law differentiates in the assessment of fairness between different states of agency (Friant-Perrot 2014). Very concretely the UCPD seems to veer between two extremes - the "reasonable well-informed, observant and circumspect" average consumer as the "prototype" of at least EU consumer law, ${ }^{35}$ and the so-called vulnerable consumer. Though the UCPD principally departs from the standard of the average consumer, it also wishes to "prevent the exploitation of consumers whose characteristics make them particularly vulnerable to unfair commercial practices" (Recital 18 UCPD).

The directive itself names several causes of vulnerability, including age, mental and physical infirmity, as well as incredulity (Art. 5(3) UCPD). The latter cause, incredulity, refers to consumers who are more likely than others to be susceptive to certain commercial influences (European Commission 2009; London Economics et al. 2016, ${ }^{36}$ for a critical analysis Duivenvoorde 2013). For the given context, the incredulity criterion seems particularly relevant as it acknowledges that the causes of vulnerability must not be limited to age or infirmity, but can also flow from the perceptibility to persuasion of certain groups or types of consumers in certain situations (London Economics et al. 2016).

Are there reasons to assume that mHealth app users form a target group that is particularly prone to persuasion, for example, in the form of personalized communication? As our survey results show, users of mHealth apps are diverse and show different levels of digital efficacy, making it difficult to speak about "the consumer of mHealth apps" (see also Bol et al. 2018). Having said so, our survey results also show some interesting differences between users and non-users of mHealth apps, with the former category reporting significantly higher levels of

\footnotetext{
35 Judgement of the Court (Fifth Chamber) of 16 July 1998, Gut Springenheide GmbH and Rudolf Tusky v Oberkreisdirektor des Kreises Steinfurt-Amt für Lebensmittelüberwachung, Case C-210/96, para. 31.

${ }^{36}$ In the study, the European Commission mentions as one out of five vulnerability dimensions the "[h]igher susceptibility to marketing practices, creating imbalances in market interactions - interpreting vulnerability as the effect of marketing practices and consumers' special susceptibility" (p. xviii).
} 
confidence in the persuasiveness of personalized content and the potential to effective change their behaviour, and yet at the same time significantly less scepticism about mHealth apps showing commercial content. More research is needed to ascertain whether this means that mHealth app users are also more open to instances of commercial persuasion in mHealth apps, and hence more vulnerable.

This also raises a more principal question about whether, and under which conditions exactly, consumers that are subject to targeted marketing practices may need to be considered to fall into the category of vulnerable consumers. mHealth apps are an interesting example here. mHealth app users are typically younger, higher educated users with higher levels of ehealth literacy skills than non-users (Bol et al. 2018), in other words, exactly the category of users that typically is not easily associated with the vulnerable consumer category. And yet, in the context of personalized (commercial) health communication, this is the type of users that is particularly concerned about living a healthy life (which is the reason why they use mHealth apps), and that exhibits disproportional trust in mHealth apps to help them achieving that goal. Those are also the users that leave the longer data trails (as opposed to, e.g., elderly users that do not use mHealth apps as much), and therefore allow advertisers and providers of mHealth apps to build more accurate profiles, identify their good and lesser active days, possibly even their moods, fears, and concerns. This knowledge, again, can be used to enable ever more precise hypernudging.

Categories of vulnerability of mHealth users that would merit more exploration could include "informational vulnerability" (London Economics et al. 2016) as a result of the extensive knowledge that advertisers can have about consumers, often unknown to consumers; vulnerability in the sense of susceptibility to personalized health market manipulation (e.g., because of reduced scepticism, more trust but also the particular value that health has for consumers); and related to that "pressure vulnerability" (Cartwright 2015) but also vulnerability in terms of the inability to choose mHealth apps that are potentially effective and/or have fairer conditions than others (e.g., because of the difficulty of understanding intrinsic data protection policies but also identifying trustworthy mHealth providers). Another important question to explore would be the role of trust in the providers of mHealth apps and their intentions in constituting vulnerability ("trust vulnerability" so to speak). Maybe even more importantly, understanding "mHealth vulnerability" can be an important first step in devising ways to mitigate the potential for abuse and unfair commercial mHealth practices (compare London Economics et al. 2016).

\section{Conclusion}

Many mHealth apps are about more than health. mHealth apps can also be part of a sophisticated, data-driven advertising strategy. This in itself is not a problem - a great deal of online content is financed by advertising. And yet, staying fit and healthy are, quite literally, of vital importance to consumers. The human urge to stay healthy, and consumers' trust in the ability of mHealth apps to help can be abused for commercial gain, for instance by pressuring consumers into making commercial decisions they would not have taken otherwise. This is why it is so important to protect trust and the autonomy of consumers' decisions in this area. In this article, we have argued that there is an important role for law, and for consumer law in particular, in establishing the boundaries between perfectly legitimate advertising strategies and unlawful data-driven manipulation of consumers' choice. 
To this end, we have combined findings from empirical, ethical, and legal research. Our survey of a representative sample of the Dutch population confirmed that many users are sceptical of mHealth apps' intentions and, moreover, draw inferences of manipulative intent. They also agree that personalized messages can be more persuasive than their nonpersonalized counterparts. Our finding that people who use mHealth apps tend to be even more convinced of the ability of personalized advertisements in mHealth apps to change their economic behaviour, while at the same time being less sceptical about the intentions of $\mathrm{mHealth}$ apps and less worried about their manipulative intent, is particularly worrying. There is at least the possibility that this group of users, who do not worry about the practices of mHealth apps, is particularly susceptible to data-driven advertising. In the article we argue that it is this group of users - media literate, tech reliant, health conscious, and active data sharers - that is also at danger of being particular vulnerable to unfair commercial practices. It is therefore important to have a solid legal framework in place that guarantees fairness in the commercial dealings between mHealth app providers and their consumers.

So far, much of the legal discussion about the use of data-driven targeting and advertising strategies has focused on the area of data protection law. The resulting data protection law analyses focus on informational privacy and often boil down to the call to give users control over who can use their data and for what purposes. Using the example of mHealth apps, we demonstrate that another important concern is to protect the decisional privacy of consumers, i.e., the ability to take decisions free from manipulation and undue influence. Unfair commercial practice law is a particularly useful legal regime in this regard, precisely because protecting the autonomy of consumers' decision-making and banning undue influence is central to unfair commercial practice law.

One major challenge of applying unfair commercial practice law in the case of mHealth apps is the lack of a clear conception of "autonomy." We have therefore proposed a new and innovative concretization of autonomy. Based on a long tradition of thinking about the concept of autonomy in philosophy, we identified three essential requirements for autonomous decision-making, which we called independence, authenticity, and options. We then showed how using these criteria can help to identify instances of data-driven targeting of mHealth users that cross the border into unfair and manipulative behaviour.

Specifically, our analysis suggests that mHealth app users must be informed about the merging of health content and commercial practices, similar to the way that users must already be informed about the merging of commercial and editorial content. Not doing so conflicts with the independence and authenticity requirements for user autonomy, and constitutes an unfair commercial practice. Similarly, we found that labelling mHealth apps as being free of charge, while in reality they collect personal data, including for the purposes of personalized advertising, is misleading. It is therefore important that - in the mHealth app context especially-every possible commercial influence on the user's behaviour is clearly labelled as such. Another key finding of our analysis is that instrumentalizing the deep knowledge that collecting consumer data can give, and using their anxiety to live a healthy life for commercial ends, can constitute an aggressive practice if it deprives consumers factually of choice, abuses their trust in the integrity and usefulness of the app for health purposes, or tinkers with the authenticity of their decisions.

mHealth apps can be a useful instrument for consumers to monitor and improve their health and fitness. Technologically assisted health self-management is also an important element in broader policies aimed at using technology for good. Given these great promises of mHealth 
apps, it is even more important to create a situation in which users can trust that it is indeed their health that mHealth apps are targeting, and not their purse.

\section{Appendix: Methods of the Empirical Study}

\section{Recruitment and Procedure}

As part of a larger panel wave study, we recruited participants through CentERdata's LISSPANEL, which comprised a representative sample of the Dutch population. A total of 1288 panel members $(90.0 \%)$ responded to the invitation to participate in our online survey. We asked respondents about their use of smart devices (i.e., smartphones, tablets, and wearables). Respondents who did not report to have a smart device were redirected to the end of the survey $(n=234,18.2 \%)$. The questionnaire continued with questions about the use of mHealth apps, followed by cognitive, affective, and behavioural components of their attitudes towards mHealth apps. Of the eligible sample (i.e., those with a smart device, $n=1054,81.8 \%), 25$ participants $(2.4 \%)$ were excluded as they skipped a substantial part of the questionnaire to get to the end $(n=13)$ or reported having mHealth apps on their smart device, but filled out other types of apps when they were asked what kind of mHealth apps they had $(n=12)$. This resulted in a final sample of 1029 adults for statistical analyses. Ethical approval for the study was obtained from the institutional review board of the authors' university.

\section{Measurements}

mHealth App Use Respondents were asked to take their smart device(s), and to indicate which mHealth apps they had installed on their smart device(s). For each mHealth app, respondents were asked to indicate on a scale from "almost every day" to "never" how often they used this app.

Cognitive Attitude Component The cognitive component was measured by respondents' perceived interest of the mHealth app provider. We proposed the statement: "The main interest of app developers is the improvement of the user's health," and asked respondents to rate what they thought on a scale from 1 "totally disagree" to 7 "totally agree." In addition, respondents were asked to justify their numeric answer with a written description of their thinking.

Affective Attitude Component We assessed the user's affective attitude towards mHealth apps using three measurements. First, we assessed users' scepticism towards the merging of commercial and health content using an adapted version of the scepticism towards ads subscale of the dispositional persuasion knowledge scale ("PKS," see Boerman et al. 2017). The following text was used to introduce the scale: "mHealth apps are often offered for free. This is possible because advertisements are shown within these apps. I think that showing advertisements in mHealth apps is..." The scale included eight items, such as "dishonest" versus "honest" $(\alpha=0.961)$, and were assessed on 7-point semantic differential scales. Second, we measured respondents' perceived manipulative intent with six items (Campbell 1995). Items included "mHealth 
apps try to manipulate people in ways I do not like" $(\alpha=0.724)$ and were assessed on a scale from 1 "totally disagree" to 7 "totally agree." Third, we asked about respondents' feelings regarding receiving personalized commercial content (i.e., personalized ads) in mHealth apps, using the statement "I prefer personalized ads over generic ads." Besides the assessment on a scale from 1 "totally disagree" to 7 "totally agree," respondents were given the option to expand on their answer in a written comment.

Behavioural Attitude Component We measured the behavioural attitude component with two statements, which could both be rated on a scale from 1 "totally disagree" to 7 "totally agree," as well as the opportunity to provide written comments. The statements included "Personalised ads are more persuasive than generic ads" and "Personalised ads are better capable of influencing my behaviour than generic ads."

\section{Statistical Analyses}

Based on the mHealth app use measurement, we categorized respondents into users and non-users of mHealth apps. Those who indicated to have mHealth apps installed on their smart device, but reported to never use them, were categorized as non-users. We conducted descriptive analyses to determine mean scores and standard deviations on the cognitive, affective, and behavioural component of user attitudes regarding mHealth apps. Furthermore, we conducted chi-square tests to compare mean scores between users and non-users of mHealth apps. To analyse the written answers provided, we coded them based on the numeric answer (i.e., numeric score of 1-3 indicates a negative comment, whereas a numeric score of 5-7 indicates a positive comment). A selection of written answers was made such that these represented comments of both users and non-users of mHealth apps, younger and older respondents, and males and females.

Open Access This article is distributed under the terms of the Creative Commons Attribution 4.0 International License (http://creativecommons.org/licenses/by/4.0/), which permits unrestricted use, distribution, and reproduction in any medium, provided you give appropriate credit to the original author(s) and the source, provide a link to the Creative Commons license, and indicate if changes were made.

\section{References}

ArsTechnica (2017). Report: Facebook Helped Advertisers Target Teens Who Feel "Worthless". ArsTechnica. com, 1 May 2017. Available at https://arstechnica.com/information-technology/2017/05/facebook-helpedadvertisers-target-teens-who-feel-worthless/. Accessed 17 Oct 2017.

Boerman, S. C., Van Reijmersdal, E. A., Rozendaal, E., \& Dima, A. L. (2017). Development of the persuasion knowledge scale (PKS): A measure of consumers' knowledge of sponsored content. Paper presented at the International Conference of Research in Advertising (ICORIA), Ghent, Belgium.

Bol, N., Helberger, N., \& Van Weert, J. C. M. (2018). Differences in mobile health app use: A source of new digital inequalities? The Information Society, 34(4), 183-193.

Van Boom, W. H., Garde, A., \& Akseli, O. (2014). Introduction to 'the unfair commercial practices directive'. In W. H. Van Boom, A. Garde, \& O. Akseli (Eds.), The unfair commercial practices directive-Impact, enforcement strategies and national legal systems (pp. 1-18). Farnham: Ashgate.

Breckler, S. J. (1984). Empirical validation of affect, behavior, and cognition as distinct components of attitude. Journal of Personality and Social Psychology, 47(6), 1191-1205.

Campbell, M. C. (1995). When attention-getting advertising tactics elicit consumer inferences of manipulative intent: The importance of balancing benefits and investments. Journal of Consumer Psychology, 4(3), 225254. 
Cartwright, P. (2015). Understanding and protecting vulnerable financial consumers. Journal of Consumer Policy, 38(2), 119-138.

Christman, J. C. (1989). Introduction. In J. C. Christman (Ed.), The inner citadel: Essays on individual autonomy (pp. 3-23). Oxford: Oxford University Press.

Christman, J. C. (1991). Autonomy and personal history. Canadian Journal of Philosophy, 21(1), 1-24.

Cotte, J., Coulter, R. A., \& Moore, M. (2005). Enhancing or disrupting guilt: The role of ad credibility and perceived manipulative intent. Journal of Business Research, 58(3), 361-368.

Degli Esposti, S. (2014). When big data meets dataveillance: The hidden side of analytics. Surveillance \& Society, 12(2), 209-225.

Devisch, I. (2013). Ziek van Gezondheid: Voor Elk Probleem een Pil? Amsterdam: Bezige Bij.

Duivenvoorde, B. (2013). The protection of vulnerable consumers under the unfair commercial practices directive. Journal of European Consumer and Market Law, 2(2), 69-79.

Dworkin, G. (1989). The concept of autonomy. In J. C. Christman (Ed.), The inner citadel: Essays on individual autonomy (pp. 54-62). Oxford: Oxford University Press.

European Comission (2009). Guidance on the implementation/application of Directive 2005/29/EC on Unfair Commercial Practices. Commission Staff Working Document, SEC(2009) 1666 final. Available at https://ec.europa.eu/transparency/regdoc/rep/2/2009/EN/2-2009-1666-EN-F-0.Pdf. Accessed 13 Apr 2018.

European Commission (2016). Guidance on the implementation/application of Directive 2005/29/EC on Unfair Commercial Practices. Available at http://ec.europa.eu/justice/consumer-marketing/files/ucp_guidance_en. pdf. Accessed 20 Oct 2017.

Eyal, N. (2014). Hooked. How to build habit-forming products. London: Penguin.

Feinberg, J. (1989). Autonomy. In J. C. Christman (Ed.), The inner citadel: Essays on individual autonomy (pp. 27-53). Oxford: Oxford University Press.

Frankfurt, H. G. (1971). Freedom of the will and the concept of a person. The Journal of Philosophy, 68(1), 5-20.

Friant-Perrot, M. (2014). The vulnerable consumer in the UCPD and other provisions of EU law. In W. van Boom, A. Garde, \& O. Akseli (Eds.), The European unfair commercial practices directive: Impact, enforcement and national legal systems (pp. 89-106). London: Routledge.

Gómez Pomar, F. (2006). The unfair commercial practices directive: A law and economics perspective. European Review of Contract Law, 1, 4-34.

Habersack, M. (2000). The doorstep selling directive and mortgage loan contracts. European Business Law Review, 11, 392-402.

Hansen, P. G., \& Jespersen, A. M. (2013). Nudge and the manipulation of choice. A framework for the responsible use of the nudge approach to behaviour change in public policy. European Journal of Risk Regulation, 1, 3-28.

Hanson, J. D., \& Kysar, D. A. (1999). Taking behavioralism seriously: The problem of market manipulation. New York University Law Review, 74, 630-749.

Harcourt, B. E. (2015). Exposed: Desire and disobedience in the digital age. Cambridge: Harvard University Press.

Howells, G. (2006). Aggressive commercial practices. In G. Howells, H. W. Micklitz, \& T. Wilhelmsson (Eds.), European fair trading law: The unfair commercial practices directive (pp. 167-194). London: Routledge.

Hyman, D. A., Franklyn, D., Yee, C., \& Rahmati, M. (2017). Going native: Can consumers recognize native advertising? Does it matter? Yale Journal of Law \& Technology, 19, 77-112.

Incardona, R., \& Poncibò, C. (2007). The average consumer, the unfair commercial practices directive, and the cognitive revolution. Journal of Consumer Policy, 30, 21-38.

Kabel, J. J. C. (2008). Audiovisual media services and the unfair commercial practices directive. IRIS plus, 8, 2-8.

Kahneman, D. (2011). Thinking, fast and slow. New York: Macmillan.

Kaptein, M. (2015). Persuasion profiling: How the internet knows what makes you tick. Amsterdam: Business Contact Publishers.

Kaptein, M., Markopoulos, P., De Ruyter, B., \& Aarts, E. (2015). Personalizing persuasive technologies: Explicit and implicit personalization using persuasion profiles. International Journal of Human-Computer Studies, $77,38-51$.

Krebs, P., Prochaska, J. O., \& Rossi, J. S. (2010). A meta-analysis of computer-tailored interventions for health behaviour change. Preventive Medicine, 51(3), 214-221.

Kreuter, M. W., Strecher, V. J., \& Glassman, B. (1999). One size does not fit all: The case for tailoring print materials. Annals of Behavioural Medicine, 21(4), 276-283.

Kroeze, W., Werkman, A., \& Brug, J. (2006). A systematic review of randomized trials on the effectiveness of computer-tailored education on physical activity and dietary behaviors. Annals of Behavioural Medicine, 31(3), 205-223. 
London Economics, VVA Consulting, \& Ipsos Mori consortium (2016). Consumer vulnerability across key markets in the European Union. Study for the European Commission, DG Justice and Consumers, Brussels. Available at https://publications.europa.eu/en/publication-detail/-/publication/d1af2b47-9a83-11e6-9bca-01 aa75ed71a1. Accessed 11 Apr 2018.

Lustria, M. L. A., Noar, S. M., Cortese, J., Van Stee, S. K., Glueckauf, R. L., \& Lee, J. A. (2013). A metaanalysis of web-delivered tailored health behavior change interventions. Journal of Health Communication, 18(9), 1039-1069.

Mackenzie, C., \& Stoljar, N. (2000). Relational autonomy: Feminist perspectives on autonomy, agency, and the social self. New York: Oxford University Press.

Micklitz, H. W. (2006). The general clause on unfair practices. In G. Howells, H. W. Micklitz, \& T. Wilhelmsson (Eds.), European fair trading law: The unfair commercial practices directive (pp. 83-122). London: Routledge.

News.com.au (2017). Leaked Document Reveals Facebook Conducted Research to Target Emotionally Vulnerable and Insecure Youth. News.com.au, 1 May 2017. Available at http://www.news.com. $\mathrm{au} /$ technology/online/social/leaked-document-reveals-facebook-conducted-research-to-target-emotionallyvulnerable-and-insecure-youth/news-story/d256f850be6b1c8a21aec6e32dae16fd. Accessed 17 Oct 2017.

Noar, S. M., Benac, C. N., \& Harris, M. S. (2007). Does tailoring matter? Meta-analytic review of tailored print health behavior change interventions. Psychological Bulletin, 133(4), 673-693.

Nys, T. R. V., \& Engelen, B. (2016). Judging nudging: Answering the manipulation objection. Political Studies, 65(1), 199-214.

Petty, R. D., \& Andrews, J. C. (2008). Covert marketing unmasked: A legal and regulatory guide for practices that mask marketing messages. Journal of Public Policy \& Marketing, 27(1), 7-18.

Raz, J. (1986). The morality of freedom. Oxford: Clarendon Press.

Reisch, L., Eberle, U., \& Lorek, S. (2013). Sustainable food consumption: An overview of contemporary issues and policies. Sustainability: Science, Practice \& Policy, 9(2), 7-25.

Rieder, B. (2015). On the diversity of the accountability problem-Machine learning and knowledge capitalism. Paper presented at the NYU Information Law Institute, Algorithms and Accountability Conference, New York.

Sandel, M. (1984). The procedural republic and the unencumbered self. Political Theory, 12(1), 81-96.

Sax, M. (2016). Big data: Finders keepers, losers weepers? Ethics and Information Technology, 18(1), 25-31.

Schaar, O. (2008). Article 10 (principles for advertising and teleshopping). In O. Castendyk, E. Dommering, \& A. Scheuer (Eds.), European media law (pp. 489-512). Alphen aan den Rijn: Kluwer Law International.

Schulze, R., \& Schulte-Nölke, H. (2003). Analysis of national fairness laws aimed at protecting consumers in relation to commercial practices. Brussels: European Commission. Available at https://irias.kuleuven. be/bitstream/123456789/204413/1/unfair practices en.pdf. Accessed 17 Oct 2017.

Thaler, R. H., \& Sunstein, C. R. (2008). Nudge: Improving decisions about health, wealth and happiness. London: Penguin.

Trans Atlantic Consumer Dialogue (2008) Resolution on Software Interoperability and Open Standards. Available at http://tacd.org/wp-content/uploads/2013/09/TACD-IP-04-08-Software-Interoperability-andOpen-Standards.pdf. Accessed 12 Oct 2017.

Valdman, M. (2010). Outsourcing self-government. Ethics, 120(4), 761-790.

Wilhelmsson, T. (2006a). Scope of the directive. In G. Howells, H. W. Micklitz, \& T. Wilhelmsson (Eds.), European fair trading law: The unfair commercial practices directive (pp. 49-82). London: Routledge.

Wilhelmsson, T. (2006b). Misleading practices. In G. Howells, H. W. Micklitz, \& T. Wilhelmsson (Eds.), European fair trading law: The unfair commercial practices directive (pp. 123-166). London: Routledge.

Willett, C. (2005). Autonomy and fairness: The case of public statements. In G. Howells, A. Janssen, \& R. Schulze (Eds.), Information rights and obligations: A challenge for party autonomy and transactional fairness (pp. 1-16). London: Routledge.

Willett, C. (2010). Fairness and consumer decision making under the unfair commercial practices directive. Journal of Consumer Policy, 33, 247-273.

Wojdynski, B. W., \& Evans, N. J. (2016). Going native: Effects of disclosure position and language on the recognition and evaluation of online native advertising. Journal of Advertising, 45(2), 157-168.

Yeung, K. (2017). 'Hypernudge': Big data as a mode of regulation by design. Information, Communication \& Society, 20(1), 118-136. 